\title{
SPATIOTEMPORAL VISUALIZATION OF TSUNAMI WAVES USING KML ON GOOGLE EARTH
}

\author{
H. Mohammadi ${ }^{\text {a, }}{ }^{*}$, M. R. Delavar ${ }^{\text {b }}$, M. A. Sharifi ${ }^{c}$, M. D. Pirooz ${ }^{\mathrm{d}}$ \\ ${ }^{a}$ GIS Dept, School of Surveying and Geospatial Eng. College of Eng, University of Tehran, Tehran, Iran, ho.mohammadi@ut.ac.ir \\ ${ }^{\mathrm{b}}$ Centre of Excellence in Geomatics Eng, in Disaster Management, School of Surveying and Geospatial Eng., College of Eng. University of Tehran, \\ Tehran, Iran, mdelavar@ut.ac.ir \\ c Geo-Information Science and Earth Observation, University of Twente, Twente, The Netherlands, alisharifi@itc.nl \\ d School of Civil Eng, College of Eng, University of Tehran, Tehran, Iran, mdolat@ut.ac.ir
}

\section{Commission IV, WG IV/3}

KEY WORDS: Tsunami Wave Modelling, KML, Google Earth, Spatiotemporal, Visualization

\begin{abstract}
:
Disaster risk is a function of hazard and vulnerability. Risk is defined as the expected losses, including lives, personal injuries, property damages, and economic disruptions, due to a particular hazard for a given area and time period. Risk assessment is one of the key elements of a natural disaster management strategy as it allows for better disaster mitigation and preparation. It provides input for informed decision making, and increases risk awareness among decision makers and other stakeholders. Virtual globes such as Google Earth can be used as a visualization tool. Proper spatiotemporal graphical representations of the concerned risk significantly reduces the amount of effort to visualize the impact of the risk and improves the efficiency of the decision-making process to mitigate the impact of the risk. The spatiotemporal visualization of tsunami waves for disaster management process is an attractive topic in geosciences to assist investigation of areas at tsunami risk. In this paper, a method for coupling virtual globes with tsunami wave arrival time models is presented. In this process we have shown 2D+Time of tsunami waves for propagation and inundation of tsunami waves, both coastal line deformation, and the flooded areas. In addition, the worst case scenario of tsunami on Chabahar port derived from tsunami modelling is also presented using KML on google earth.
\end{abstract}

* Corresponding author 


\section{INTRODUCTION}

Tsunami is one of the most important marine hazards generally triggered by earthquakes and/or submarine/subaerial landslides. In general, tsunami might affect not only the areas where it is generated but also substantial distance away from the generation region. The tsunami modeling and risk analysis are necessary for better disaster preparedness and proper mitigation more effectiveness, as well as understanding of process, wider awareness, and undertaking effective mitigation strategies. Modeling is one of the essential components of tsunami studies at scientific and operational levels. Tsunami modeling includes exchange and enhance of available earthquake and tsunami data, bathymetric and topographic data in sufficient resolution, selection of possible or credible tsunami scenarios, selection and application of the validated and verified numerical tools for tsunami generation, propagation, inundation and visualization. The generation phase includes calculation of the vertical seafloor deformation due to a submarine earthquake (Hydarzadeh et al., 2009). Then, the seafloor deformation field is translated directly to the water surface and is used as an initial condition for the propagation and run-up phases. Tsunami travel outward in all directions from the generation area, with the direction of the main energy propagation generally being orthogonal to the direction of the earthquake fracture zone (Selvan and Kankara. 2016). The speed of tsunami waves depends on the depth of water, so that the waves undergo acceleration and deceleration in passing over an ocean bottom of varying depth. In the deep and open ocean, the tsunami wave travel at speeds of 500 to $1000 \mathrm{~km} / \mathrm{hr}$ (Selvan and Kankara. 2016). However, in the open ocean, the height of the waves is generally about 30 to $40 \mathrm{~cm}$ even for the most destructive distant tsunami, and so the waves pass unnoticed. Specifically tsunami waves undergo a process of wave refraction and reflection throughout their travel. Tsunami are unique in that wave disturbance extends through the entire water column from sea surface to the ocean bottom. The propagation of tsunami wave from the deep water undergoes change, causing increase in the wave height at the coast due to the nearshore bathymetry and coastal morphology (Titov and Synolakis, 1997). An inundation model then takes the deep ocean tsunami and calculates how the wave shoals and runs up onto dry land (Dominey et al., 2006). Inundation modeling requires highly detailed bathymetry and knowledge of physical properties such as basal friction.

\section{TSUANMI MODELLING}

Tsunami generation phase forms the first stage in the modelling of tsunami, and includes the calculation of the initial disturbance of ocean surface due to the earthquake-triggered deformation of the seafloor using this seismic parameters (Hydarzadeh et al., 2009). IN this research, the algorithm of Okada (1985) was used to calculate the seafloor deformation. This algorithm is based on seismic parameters that include the strike, dip, and slip angles the amount of slip, the dimensions (Length and width) of the ruptured area, and the earthquake depth. We used this parameters as worst case scenario parameters into the numerical tsunami simulation modeling, shown in table 1. For propagation and inundation modelling there are several types of numerical models developed for estimating numerical simulation of non-linear waves of tsunamis. Numerical modeling employed, in this study was COMCOT (Cornell Multi-grid Coupled Tsunami) model, which developed in FORTRAN programming language by Xiaoming Wang at Institute of Geological \& Nuclear Science, New Zealand (Wang. X., 2008). The COMCOT model using nonlinear shallow water equation (NSWE) is used to handle simulation of propagation and coastal amplification of tsunami. This model solves the governing equations by the finite difference technique with leap-frog scheme. It can compute the wave propagation at all locations, even at shallow and land regions within the limitations of grid size (Imamura, 1996).

In this study, two types of bathymetric and topographic nested data with different grid sizes, are employed, for deep water. The dataset was complemented with 30 arc second resolution $\sim 980$ meters from General Bathymetric Chart of the Ocean (GEBCO, http://www.gebco.net/data_and_products/gridded_bat hymetry_data/). The total number of grid points in the computational domain was 1267, 666 consisting of 843822 points. and for the near-shore zone, the second data source provided through digitized nautical charts from the National Cartographic Center (NCC) of Iran digital atlas with $\sim 0.5$ arc second (15 meters resolution). The total number of grid points in the computational domain was 1085, 435 consisting of 491505 points. Both of the two type of data types have been used for generation of the worst case tsunami scenario. The time step between two sequential output file was 20.0 seconds to satisfy the stability condition. The duration time of wave propagation and inundation for two hours tsunami simulation modeling took 3 hours 44 minutes in a computer with Core i7 and 4GB Ram. Figure 1, illustrate the snapshots of the water surface displacement at generation time for the employed data simulated based on worst case scenario for Makran tsunami simulation.

\section{VISUALIZATION}

The tsunami modelling output are sequential static files, representing the movement of tsunami waves in propagation and inundation phases for specific time step. Therefore, if we would like to simulation tsunami for two hours after generation phase, and time step between two output file of 20 second, then we have 360 output files( at the moment of generation phase to two hour after generation phase). Figure 1 , is the output file at time of generation phase. To create spatiotemporal visualization from the output model on the google earth, some specific processes have been implemented as explained in the following.

\begin{tabular}{|c|c|c|c|c|c|c|c|c|c|}
\hline \multicolumn{2}{|c|}{ Location (epicentre) } & \multirow[b]{2}{*}{$\operatorname{Dip}\left({ }^{\circ}\right)$} & \multirow[b]{2}{*}{ Slip $\left(^{\circ}\right)$} & \multirow[b]{2}{*}{ Strike $\left(^{\circ}\right)$} & \multirow[b]{2}{*}{ Depth (Km) } & \multirow[b]{2}{*}{ Length (Km) } & \multirow[b]{2}{*}{ Width(Km) } & \multirow[b]{2}{*}{ Slip(m) } & \multirow[b]{2}{*}{ Moment(N m) ${ }^{\mathrm{a}}$} \\
\hline Lon. $\left({ }^{\circ} \mathrm{E}\right)$ & Lat. $\left({ }^{\circ} \mathrm{N}\right)$ & & & & & & & & \\
\hline 60.4832 & 24.35826 & 10 & 90 & 270 & 30 & 130 & 70 & 15 & $1.8 \times 10^{21}$ \\
\hline
\end{tabular}

Table 1. Seismic parameters of the Makran tsunami of worst case scenario

${ }^{a}$ The rigidity of the earth is about: $3.0 \times 1010 \mathrm{~N} / \mathrm{m}^{2}$ in the Makran region 


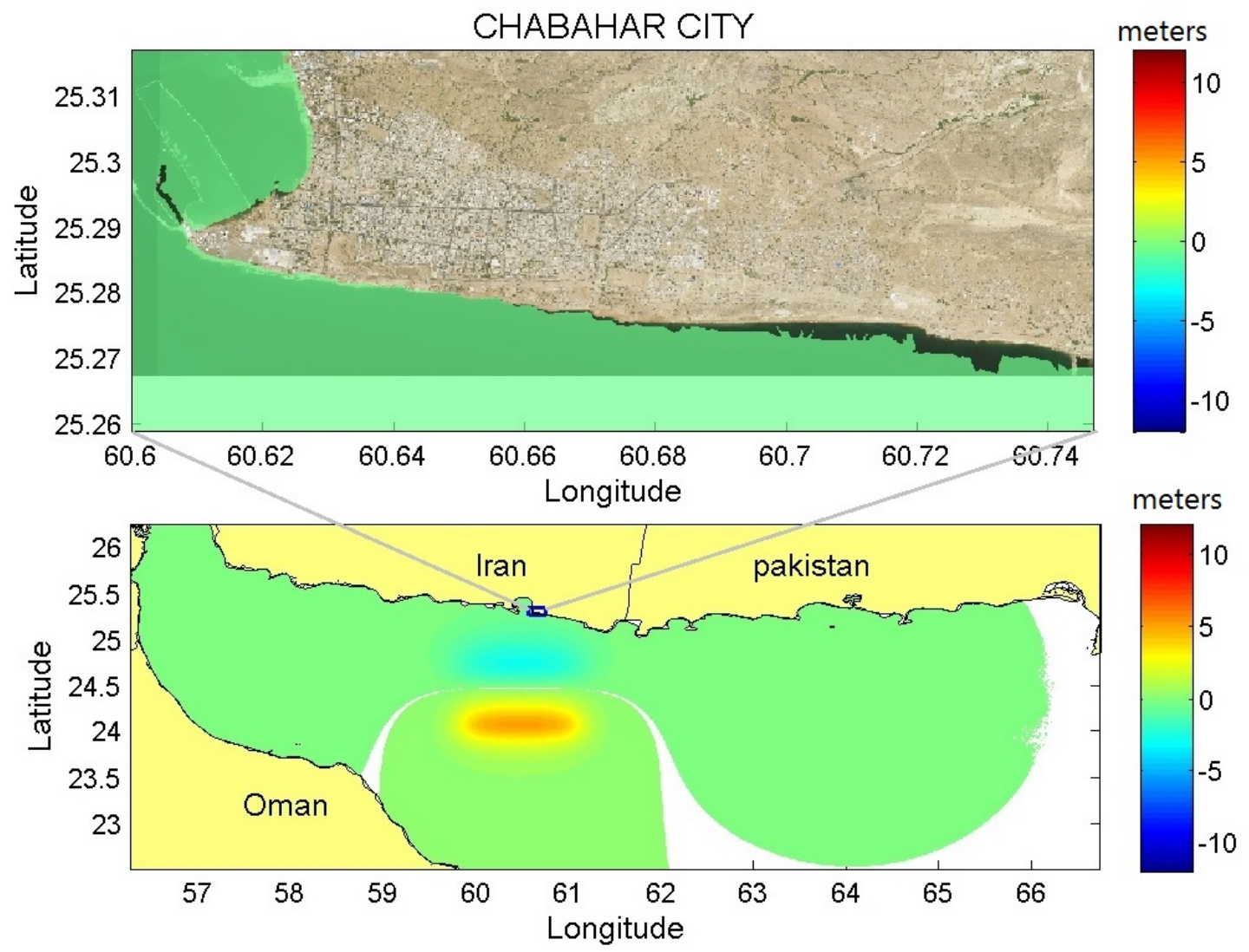

Figure 1. Output tsunami modeling at generation time step. The down image illustrate sea level deformation in effect of worst case scenario tsunami in Makran fults with 30 arc seconds (980 meters) resulation and upward image illustrate coastal level deformation in effect worst case tsunami scenario in Chabahar port, with 15 meters resulation, proper for tracking inundation visualization and coastal deformation tsunami wave affected

\subsection{Spatial and Spatiotemporal Tsunami Modelling}

According to Erwig et al. (1999) Spatiotemporal data sets and corresponding databases represent two major groups of features: (1) moving or dynamic objects (discrete or vector geometries), and (2) regions or fields (continuous). Objects and fields can be further based on regular or irregular sampling systems and representation models. Many features can be modeled and represented both using discrete (vector) and continuous (raster) GIS models. Tsunami waves can be represented as regions. Also coastal lines movement affecting the tsunami inundation can be represented as polylines. For an introduction to the spatial and spatiotemporal objects and fields see Galton (2004). A schematic overview of 2D, 3D, 2D+T and 3D+T combination of spatiotemporal object types is given in Table 2. This paper has considered $2 \mathrm{D}+\mathrm{T}$ for tsunami wave, spatiotemporal visualization of the following:

1- Coastal line temporal visualization

2- Temporal of the propagation and Inundation tsunami waves visualization.

For coastal line temporal visualization, at the first step, coastal lines from each output file data should be extracted. Due to this process we design a model builder to extract the coastal line for each output file data. Figure 2, shows this flow chart. After extracting coastal line for each time step, time-step for each specific output file should be introduced. There are some standards format for date and time, yyyymmddhhmmss where; ууyу 4-digit year, $\mathrm{mm}$ 2-digit month,

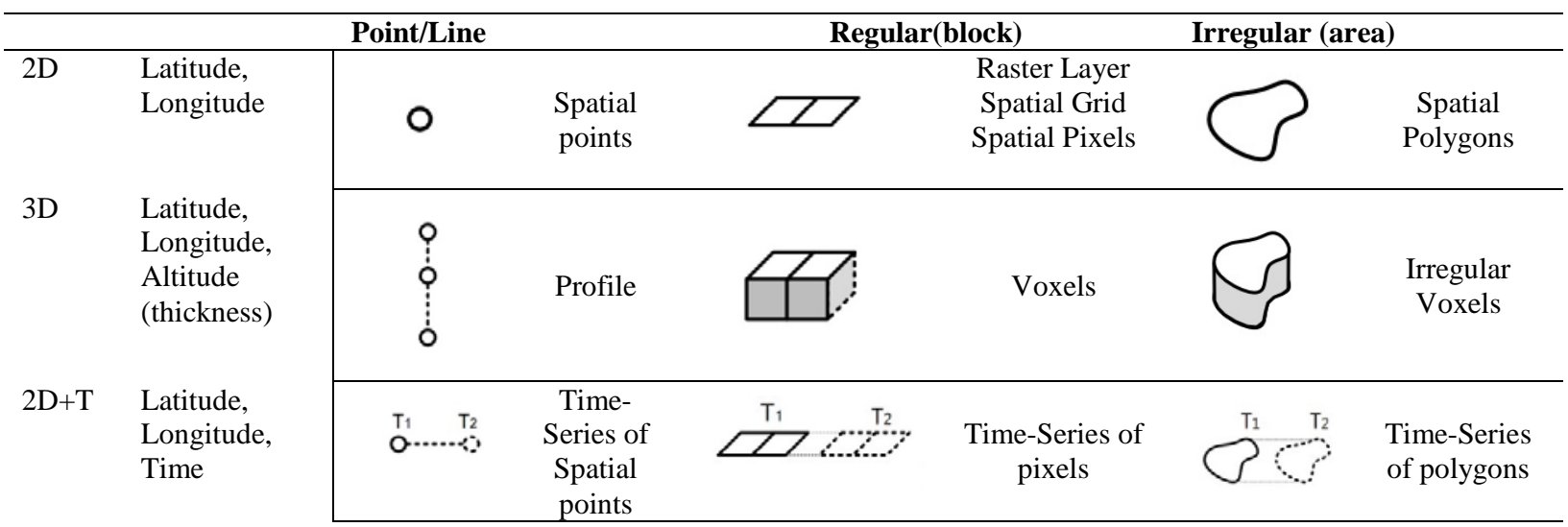




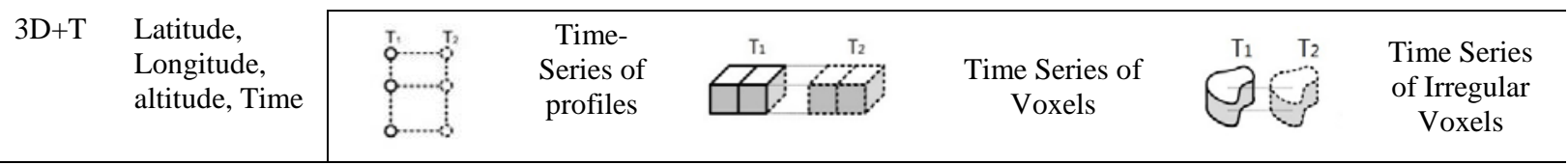

Table 2. Different types of spatiotemporal data (Tomislav et al., 2015)

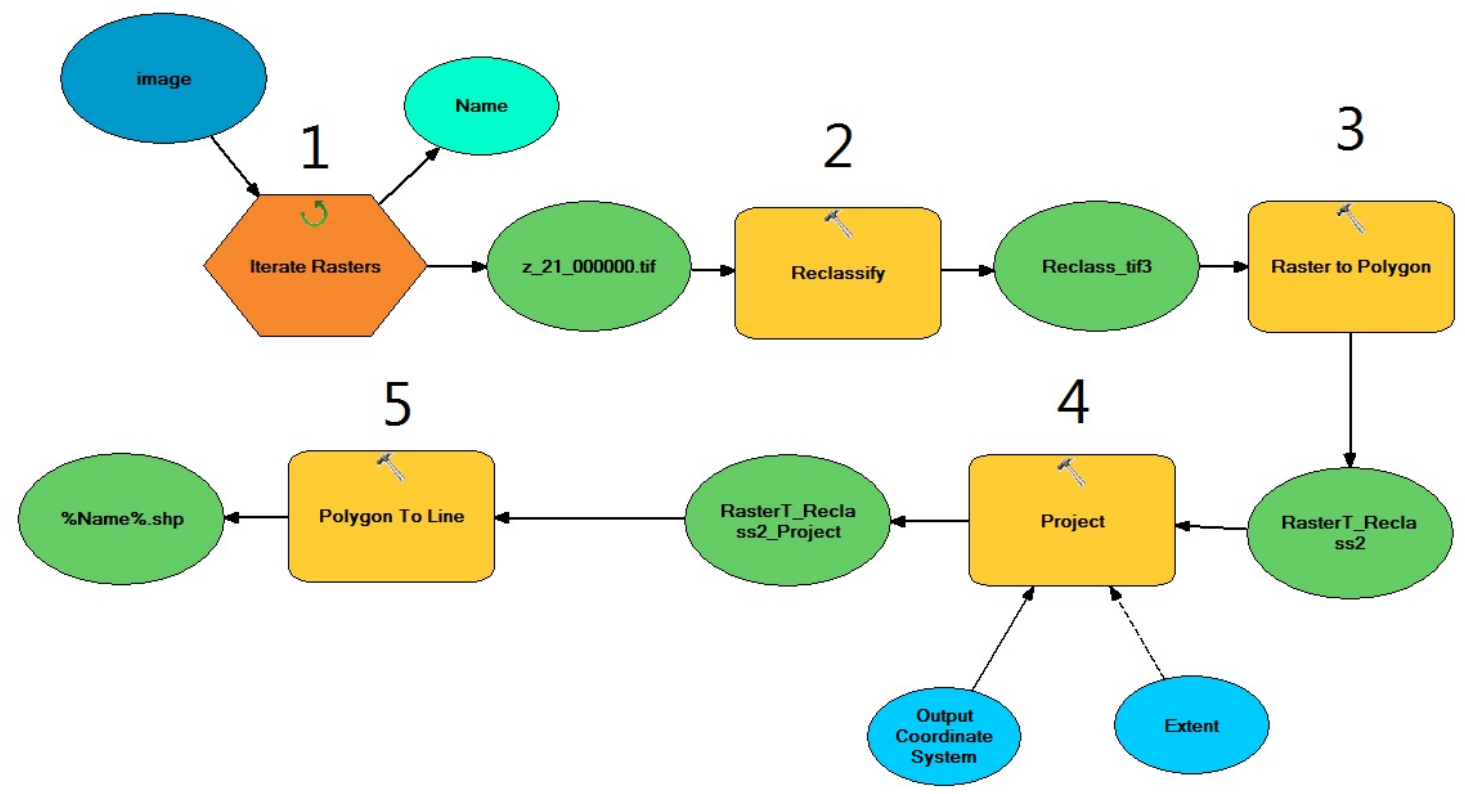

Figure 2. Flowchart of extracting coastal line for all output file near Chabahar port (15 meters resolution). According to this Figure, 1. Iteration must be dong for whole output file, 2. Reclassify each output data to extract the value of sea deformation data (deletion Null data), 3. Convert each output data (raster) to polygon, 4. Checking extent and coordinate system, 5. Convert of each polygon to line; extracting boundary line (coastal line).

dd 2-digit day of mouth, hh 2-digit hour of a 24-hour clock, mm 2-digit minutes and ss 2-digit seconds. Optional fraction of a second, up to 9 digits or nanosecond resolution. Additional fractional digits are accepted, but only 9 fractional digits are kept during temporal arithmetic. According to this standard, we define a column for each of output files and then adding own specific time step for each output file. Finally whole output files were merged into one file geodatabase. So far we have extracted the coastal line data that has time attribute for own different time step. The next process is to convert these data to KML (Keyhole markup language) and show the temporal animation.

\section{GOOGLE EARTH AND KML}

Google Earth is a Web based mapping software (also characterized as a virtual globe program) that portrays a visually accurate representation of the entire Earth surface using satellite images, aerial photographs and GIS data (Stefanakis and Patroumpas. 2008).

KML is an (eXtensible Markup Language) XML-based format (or language) intended to store data for use within the Google Earth $^{\mathrm{TM}}$ and Google Maps ${ }^{\mathrm{TM}}$ application (Stefanakis and Patroumpas. 2008). The name "Keyhole" comes from the name of the original developers of the KML format and Google Earth product. KMZ (the zip compression format of KML) is an alternate from for a KML format dataset. A KMZ dataset is simply a KML dataset compressed by a ZIP type program and renamed with a new file extension. KMZ is most frequently used as a means to store a set of raster images; the KMZ (zip) folder store the raster files (as JPEG or GeoTIFF) plus a KML file that reference them. Most virtual globs adopt KML as the format for describing geospatial objects, and render the objects as specified in the KML file. This type of file can be created to manipulate the KML text files either manually or using a computer program. The main reason for its popularity is that KML is used as the basic format for managing three dimensional geospatial data in Google Earth. As KML is based on XML standard, it uses a tag-based structure with nested elements and attributes. The root element is named object and has an identifier. In version 2.1 (KML 2007), object element has six extensions to the following abstract elements including feature, geometry, color style, style selector, time primitive and schema field. Geometry elements may accommodate the types of Point, line string, linear ring, polygon, multi geometry and model. KML, using a standardized syntax conforming to XML represents a hierarchical data system (Wernecke, 2009) where geospatial objects can be populated in a nested structure. It has been developed and maintained by the World Wide Web Consortium (W3C 2007). XML has the following features, which made it so widely accepted by the Web community: (a) it is portable; (b) it utilizes Unicode; (c) it is platform independent; (d) it is human readable (it is a pure and editable text); (e) it is extensible (extra information can be added to a format without breaking applications based on previous versions); and (f) it is well supported; in fact, a large number of off-the-self tools for processing XML documents exist. The content for each object must be contained between a pair of KML tags: < object > and < /object>. Table 3, lists several such objects.

$\begin{array}{ll}\text { Object } & \text { Description } \\ \text { placemark } & \text { Indication of a specific geographical location } \\ \text { points } & \text { Discreate points with format Long, Lat, Alt where the } \\ & \text { Altitude Alt is optional }\end{array}$


interoperability challenges. It is classified as a Spatial ETL (Extract-Transform-Load) tool, designed to help users for more spatial data transformation challenges than any other technology. FME is available to extract and read any format of spatial data, and then transform data to manipulate translation process, and finally write the data in any other format.

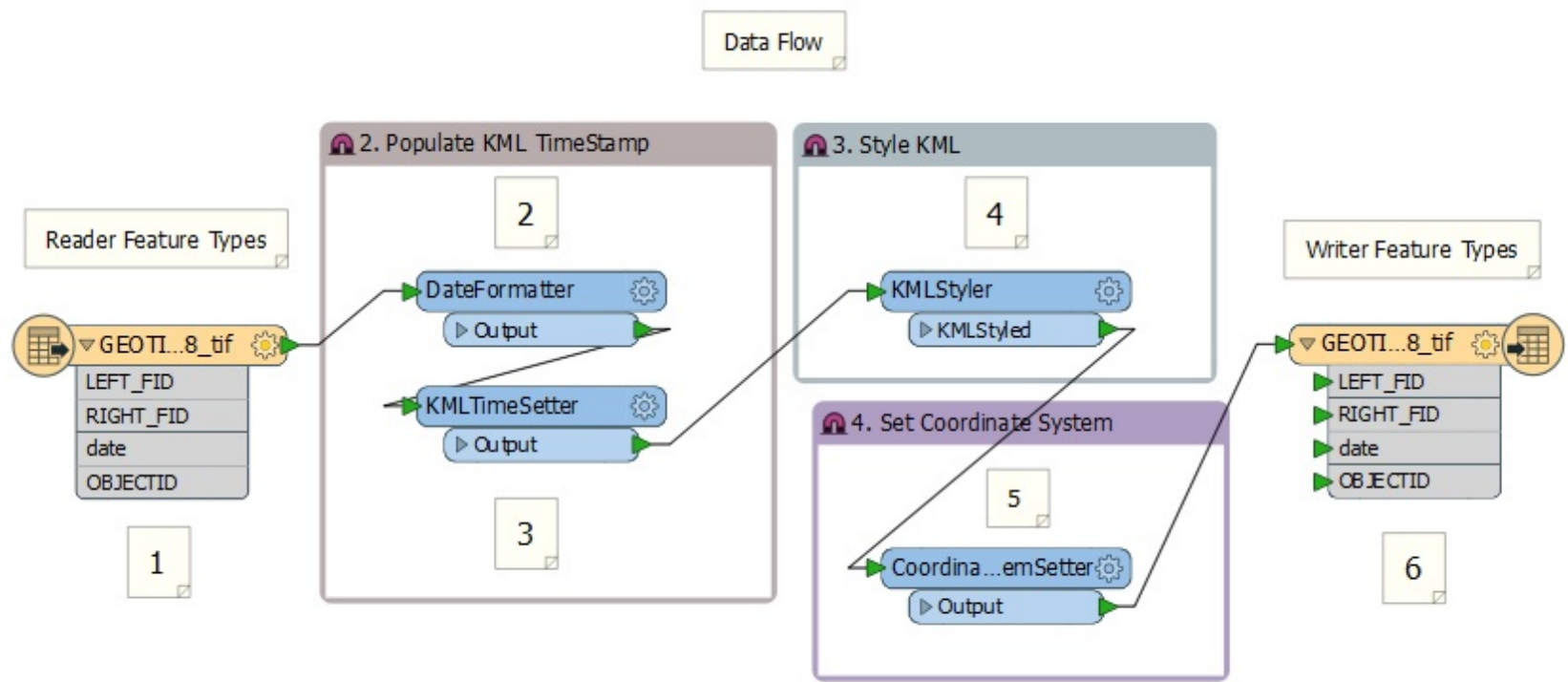

Figure 5. Flowchart of transformation of file geodatabase to KML. Using FME software. 1. Read features from the file geodatabase,

2. Format date into the KML time standard, dateTime as defined in the XML specification, 3. Sets the format attribute kml_timestamp_when (Timestamp). The transformer can also set the kml_timespan_begin and kml_timespan_end (Timespan), 4. Sets the icon for the output features, as well as the line width and colour, 5 . The source data is not coordinate system aware. The data is tagged as LL83 (google earth coordinate system) so that it can be displayed in Google Earth.

The blue line in Figure 6. Shows coastal line during tsunami simulation with 15 meters resolutions. According to this simulation, around 16 minutes and 51 seconds the coastal line has no movement into the dry lands (dry coastal region) and after this time tsunami wave passed the dry land. Figure 7, represents the coastal line affect the tsunami after 18 minutes and 20 seconds. The time bar will move slowly along the scale from the minimum to the maximum value, and features within the main display be turned on and off according to whether their time stamp (or time span) falls within the current date range.

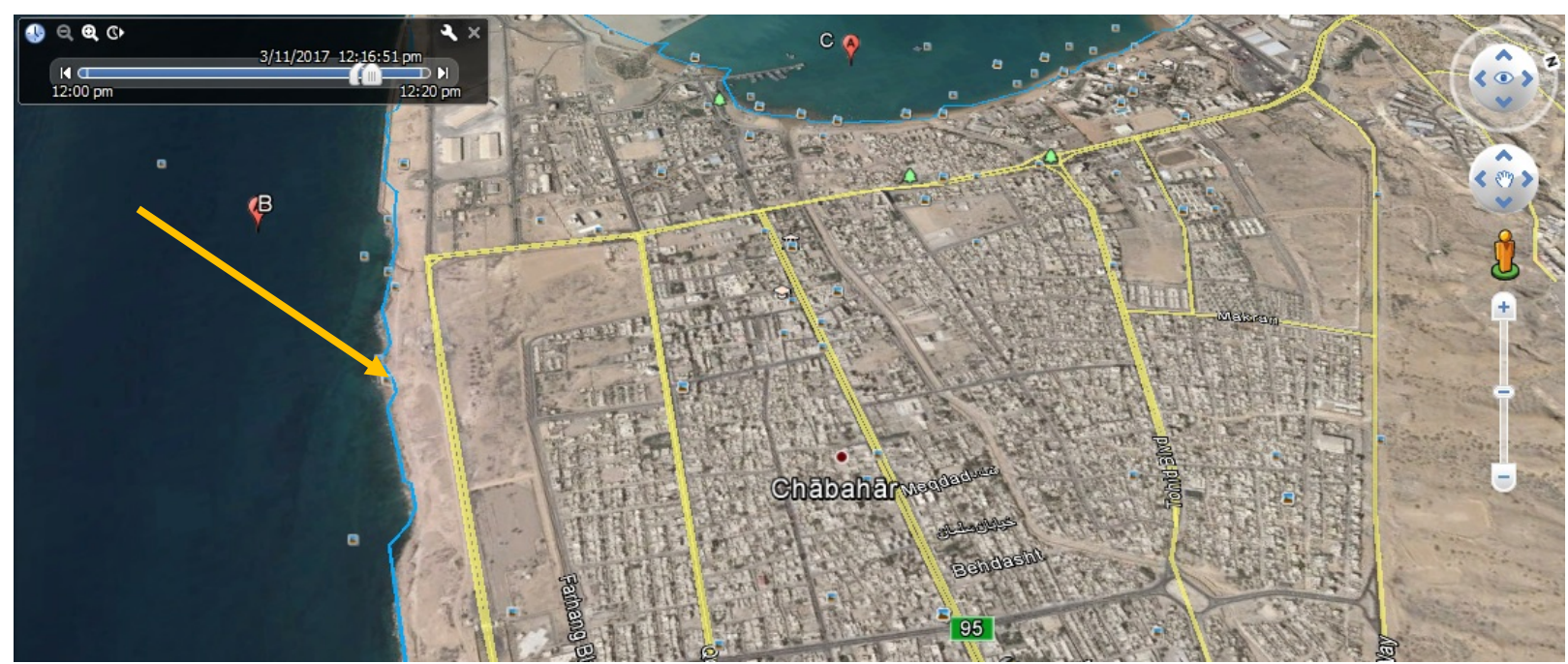

Figure 6. Chabahar port region, blue line shows the coastal line during the tsunami simulation. This photo shows 16 minutes and 51 seconds after tsunami generation. So the boundary of coastal line has no movement caused by the tsunami. 


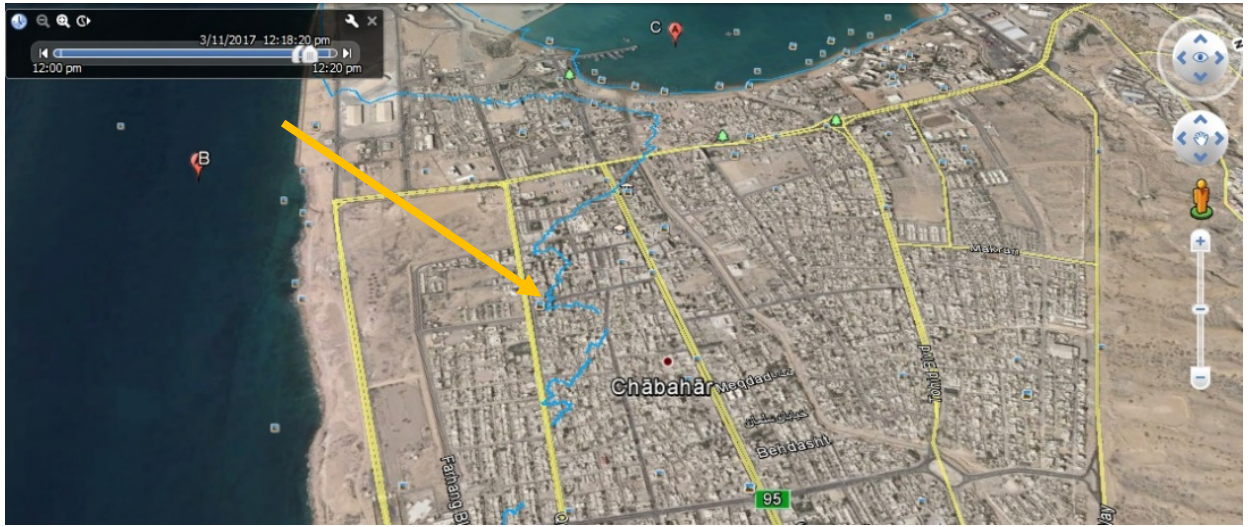

Figure 7. Chabahar port region, blue line shows the coastal line during the tsunami simulation. This photo shows 18 minutes and 20 seconds after the tsunami generation.

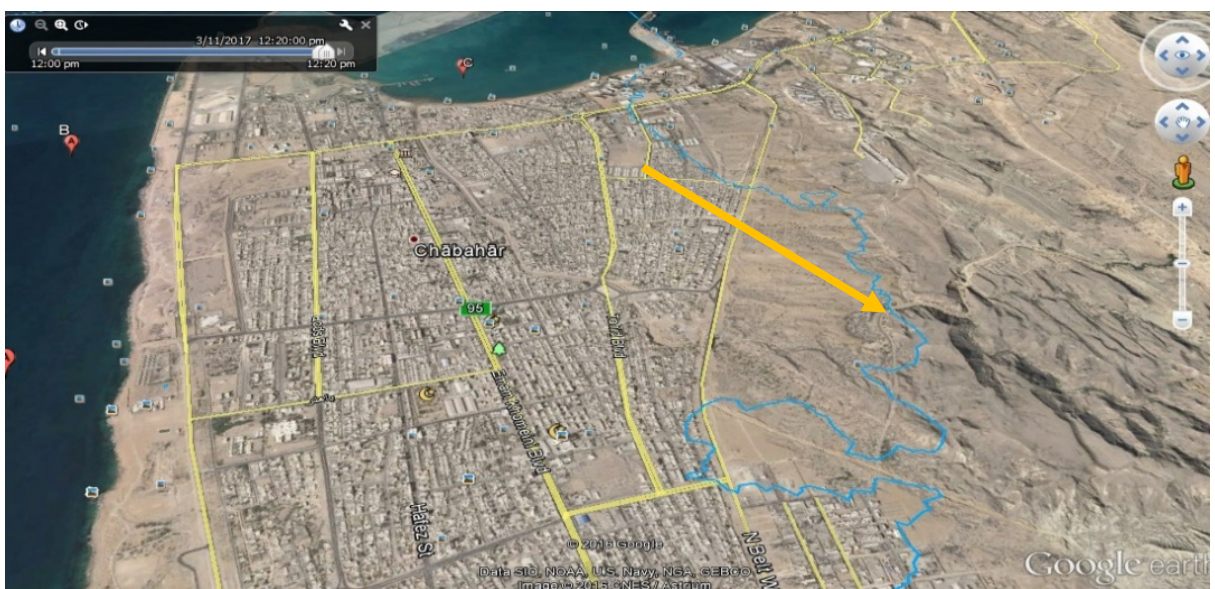

Figure 8. Chabahar port region, blue line shows the coastal line during the tsunami simulation. This photo shows 20 minutes after the tsunami generation.

For Propagation and Inundation tsunami waves temporal visualization all output files have been transformed to raster file like Portable Network Graphics (PNG) format because, to define an alpha channel for $100 \%$ transparency where no data. With height symbol, and then a raster to KML analysis line

Figure 9, represent flowchart of the transformation of PNG raster to KML using of FME. Figure 10. Represents the worst case scenario inundating tsunami wave for 18 minutes and 20 seconds after the tsunami generation time.

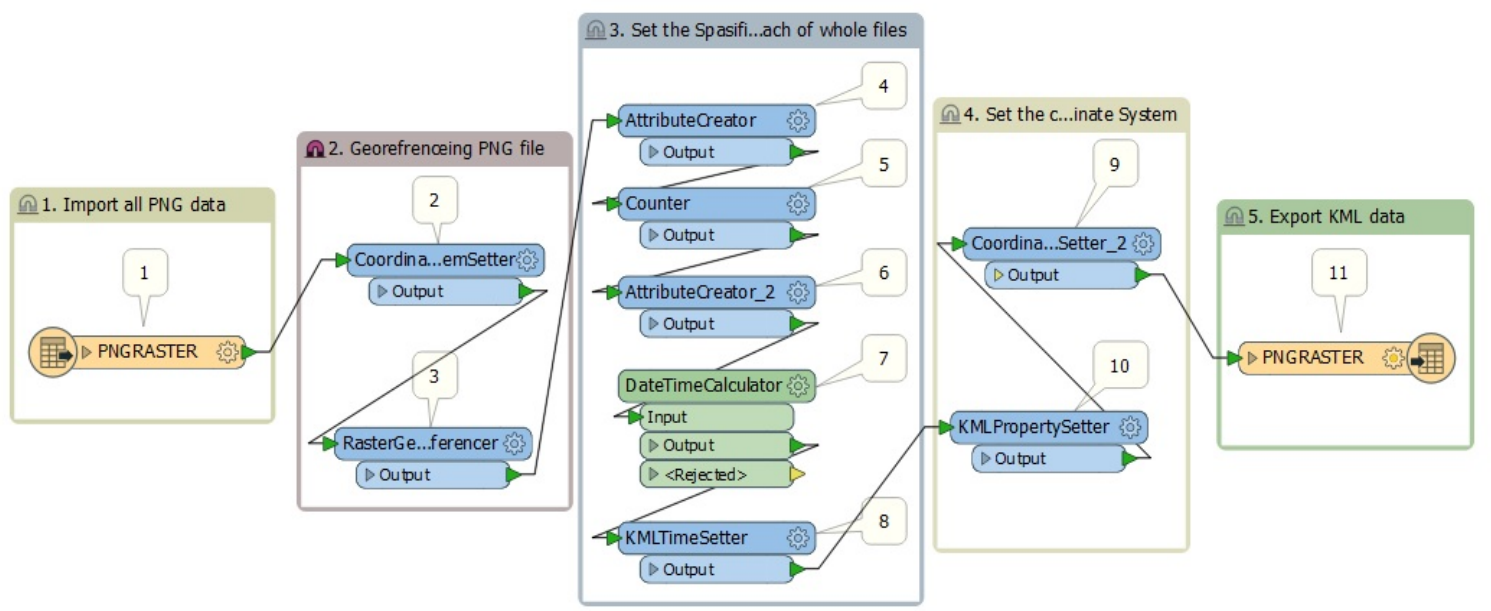

Figure 9. Flowchart of transformation of PNG raster to KML using of FME. 1, Reading each PNG file from workspace, 2. Set the coordinate system for PNG file, 3. Set the bounding box with RasterGeoreferencer according the coordinate system, 4. Set the time for each PNG file, 5. Add count to image 6. Add 20 second, between each file sequentially: @Value (_count)*20, 7. Add static interval (second) to each, 8. Set the time scale for KML, 9. Check the coordinate system, 10. Set the Altitude mode relative to ground, 11. Exports KML workspace. 


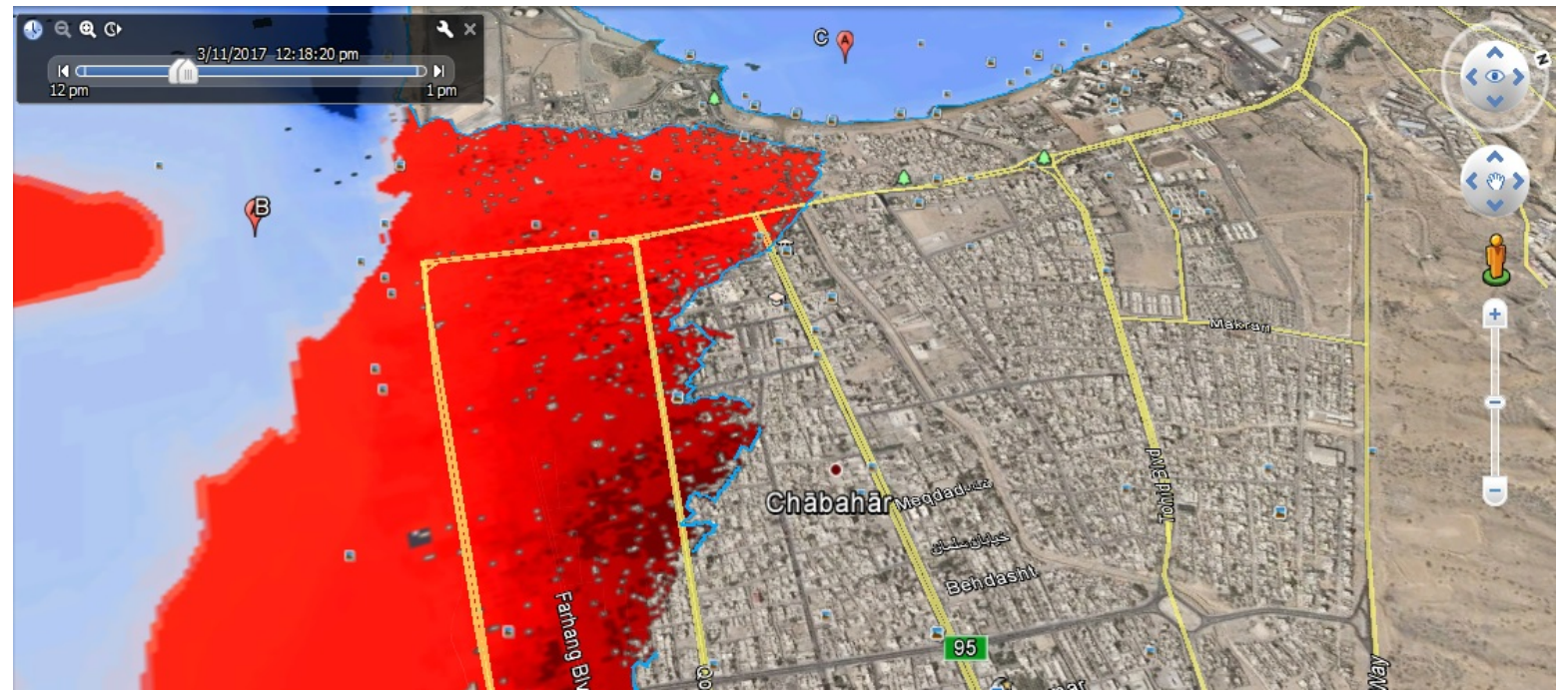

Figure 10. Tsunami waves reach to Chabahar Port during the tsunami simulation. This photo shows 18 minutes and 20 seconds after tsunami generation.

\section{Conclusion}

In this paper we have used worst case scenario to simulate worst inundation case in Chabahar port as a result of tsunami. According to Figure 6 tsunami waves will reach to Chabahar coastal line after 16 minutes and 4 minutes later tsunami wave will be inundating $3 \mathrm{Km}$ to the Chabahar port which is illustrated in figure 8.

Accuracy of tsunami modelling is directly related to the resolution of the bathymetric and topographic data used and the higher resolution data produces more accurate modelling but equally take lot of processing time.

Spatiotemporal data sets are often very large and difficult to analyse and display. However, they are fundamental for decision making to support disaster management strategy as it allows for better disaster mitigation and preparation.

Keyhole Markup Language, which is one of descriptive markup languages adopted by google earth, is capable to storage, transmission, exchange and expression of geospatial and spatiotemporal data through the web. These are vital elements in development of GIS.

Google earth provides an easy-to-use, free and interactive geospatial platform that is widely used in many aspect of disaster management, especially for spatiotemporal risk visualisation that allow the user and stake holder more interaction with and phenomena and management and mitigation of risk.

Our spatiotemporal tsunami wave's visualization method is common and capable to be used for any tsunami simulation, regardless of location's fault or seismic parameters for generation modeling phase. The numerical model that have been used here, can be used for forecasting other disaster and risk application management like flood, and storms.

\section{Reference}

Chien, N. Q., and Tan, S. K., 2011. Google earth as a tool in 2-D hydrodynamic modelling. Journal of Computer and Geosciences 37. pp. 38-46.
Dominey-Howes, D., Cummins P., and Burbidge D. 2006. Historic records of tele-tsunami in the Indian Ocean and insights from numerical modelling. Natural Hazards, DOI 10.1007/s11069-006-9042-9.

Erwig, M. G., Uting, R. H., Schneider, M., Vazirgiannis, M., 1999. SpatioTemporal Data Types: An Approach to Modelling and Querying Moving Objects in Databases. Journal of GeoInformatica, Vol. 3. pp. 269-296.

Galton, A., 2004. Fields and objects in space, time, and spacetime. Journal of spatial cognition and computation, Vol 4(1). pp. 39-68.

Heydarzadeh, M., Pirooz, M. D., Zaker, N. H., 2009. Modelling the near-field effects of the worst-case tsunami in the Makran subduction zone. Journal of Ocean Engineering Vol. 36. pp. 368-376.

Imamura, F., 1996. Review of tsunami simulation with finite difference method, in: Long Wave Run up Models, edited by Liu, F., Synolakis, C., and Yeh, H., World Scientific, pp. 25-42.

Okada, Y., 1985. Surface deformation due to shear and tensile faults in a half space. Bulletin of Seismological Society of America. Vol. 75 (4), pp. 1135-1154.

Selvan, S. Ch., and Kankara, R. S., 2016. Tsunami model simulation for 26 December 2004 and its effect on Koodankulam region of Tamil Nadu Coast, The International Journal of Ocean and Climate Systems, Vol, 7(2). pp. 62-69.

Stefanakis, E., Patroumpas, K., 2008. Google Earth and XML: Advanced Visualization and Publishing of Geographical Information, International Perspectives on maps and the Internet, Lecture notes in Geoinformation and Cartography, pp. 143-152.

Synolakis, C. E., 2003. Tsunami and seiche. In: Chen, W.F., Scawthorn, C. (Eds.), Earthquake Engineering Handbook. CRC Press. Chapter 9, pp. 1-90. 
Titov, V. V., and Synolakis, C. E., 1997. Extreme inundation flow during the Hokkaido-Nansei-Oki tsunami. Geophysical Research Letters 24, pp. 1315-1318.

Tomislav, H., Pierre. R., Beaudette. D., Pebesma. E., 2015. Plot KML; Scientific Visualization of SpatioTemporal Data. Journal of Statistical Software. Vol. 63. Issue 5.

Wang, X., 2008. Numerical modelling of surface and internal waves over shallow and inter mediate water. $\mathrm{PhD}$ thesis, Cornell University.

Wernecke, J., 2009. The KML Handbook, Geographic Visualization of the Web. Addison-Wesley, Upper Saddle River. ISBN 978-0-321-52559-8 